\title{
Polymer Characteristics Study to be Utilized as Waste to Energy Conversion System
}

\author{
Vipulpandey \\ M. Tech Scholar \\ Truba Institute of Engineering and \\ Information Technology \\ Bhopal, M.P. India \\ vipulskills@gmail.com
}

\author{
Dr. Rajeev Arya \\ Director \\ Truba Institute of Engineering and \\ Information Technology \\ Bhopal, M.P. India \\ rajeev.arya@trubainstitute.ac.in
}

\author{
Shravan Vishwakarma \\ Professor \\ Truba Institute of Engineering and \\ Information Technology \\ Bhopal, M.P. India \\ shravanmits@gmail.com
}

\begin{abstract}
The interaction between synthetic polymers and the natural environment in terms of the effects of oxygen, radiant energy, and living organisms has been extensively studied over the past two decades. However, recent trends in environmental protection have aroused great public interest. This paper introduced polymer properties such as biodegradability and the Westas energy and organic waste for fuels and chemicals. Description of bio plastics and biodegradable plastics based on polyester.
\end{abstract}

Keywords: Biodegradable Materials; Plastic; Fuels, Biomaterials.

\section{INTRODUCTION}

The history of biodegradation is relatively new. Efforts to use biodegradable materials have been significantly reduced in response to environmental concerns. In 1988, about 30 percent of the 51 billion pounds of plastic produced in the United States was used in packaging. "Large amounts of garbage have been dumped into the ocean for decades. By nature, plastics are very resistant to attacks from nature. These lightweight plastics will eventually run ashore, creating a major waste problem. The ingestion of plastic by wildlife on land and at sea is sometimes fatal. The examples are well documented. "The presence of plastic in wildlife habitats on land and water has created problems that are widely used by the environmental lobby to call for solutions from the plastics industry. The proposed solutions are recycling, incineration, composting and environmental degradation. The latter refers to both photodegradation or attack by ultraviolet radiation and biodegradation and attack by microbes.

The biodegradation of a polymeric material is based on the attack of microbes such as bacteria and fungi by enzymatic action. The end result is a complete loss of structural integrity due to a drastic decrease in molecular weight. Although plastics are by definition extremely high molecular weight and inherently inert, it is possible to synthesize new materials that degrade significantly in a short time. The first generation of biodegradable materials consisted of blends of polymers with natural food sources such as starch. The second attempt focused on inserting functional groups as ester bonds on the polymer backbone. These groups are sensitive to microbial impact. The third approach is to develop materials such as veil (hydroxybutyrate) (PHB), which are naturally synthesized by bacteria grown in fermentation vessels. These latter materials can be considered truly biodegradable. The applications of these materials are immense and range from medical applications such as surgical implants and matrices for long-term implantable controlled release of drugs, to agricultural applications such as seed pots and mulch, to numerous traditional packaging applications.

\section{LITERATURE REVIEW}

V.Boyaiah et al. [1] this study examines various waste additives together of the symbiotic processes (used in construction applications). During this study, greater emphasis is placed on environmental conditioning, prevention of pollution and minimization of waste.

F.Agostini et al. [2] this text provides an summary of the porous physical properties, phenomena, and simulation models that are studied and applied so far within the storage of biodegradable waste (BW) and summarizes the most properties of porous media and therefore the dynamics of liquids in their cavity. . The aim is to spotlight how the outline of biodegradable waste as porous media and therefore the use of porous media models can facilitate the event of latest sustainable and economical technologies for recycling BW. However, it should be noted that the shortage of physical experimental data and tailored-modeling tools has hampered the utilization of this approach.

J. H. Song et al. [3] this text examines the possible effects of biodegradable packaging materials and their waste disposal, particularly through composting. The most themes which will influence the evaluation of the benefits of those materials 
over their traditional petrochemical counterparts are presented. Specific examples come from recent research on biodegradability in simulated "home" composting systems. Consistent with the authors, biodegradable packaging materials are best fitted to single-use applications where postconsumer waste are often composted locally.

K Pikoń et al.[4] during this featured article, the event of biodegradable packaging materials made up of renewable raw materials has received more attention, especially within the EU. the utilization of biodegradable materials is predicted to possess a lower environmental impact than conventional materials made up of non-renewable raw materials. Here, in further discussion on the consequences of replacing petroleum materials with biodegradable materials.

\section{Polymer Characteristics AND BIODEGRADABILITY}

The sensitivity to microbial attack depends on the structure of the polymer. High molecular weight synthetic polymers as a class resist biodegradation. Exceptions are polymers with aliphatic esters in the main chain and polyurethane-based on polyester diols. However, mixed bonded polymers such as $\mathrm{C}$ $\mathrm{O}$ and $\mathrm{C}-\mathrm{N}$ show greater susceptibility to biodegradation than polymers with only $\mathrm{C}-\mathrm{C}$ bonds. Therefore, aliphatic polyesters (eg, polycaprolactone, polyethylene adipate, and polyglycolic acid) are easily attacked. Polyethylene oxide with its $\mathrm{C}-0$ bonds is also sensitive. Aromatic polyesters are resistant to attack. Polyamide plastics have sometimes been classified as biodegradable, although they are considered relatively resistant to microbial attack.

The biodegradability of polymers is generally attributed to enzymes that normally act on natural substrates. Hydrolases, which break down esters and amides, are essential for the well-being of the soil and aquatic microorganisms. These enzymes are found in the extracellular environment, presumably to break down high molecular weight products for transport into cells and use. The activity of these enzymes on synthetic polymers is only random and is related to the "free" specificity of the enzymes for the substrates. The enzyme can also be used to explain biodegradation. First, enzymes require access to polymer sites for their activity. This requires that the enzymes are coenzymes (extracellular) and are able to easily penetrate polymers at the site of action. Obviously, the latter requirement is unlikely for waterinsoluble polymers with limited pore space for enzymatic penetration. Secondly, there must be chemical groups that are susceptible to enzymatic attacks. The resistance of polyethylene to microbial attack is an example. Repeated C$\mathrm{C}$ bonds cannot be attached. An analogy can be made with the microbial degradation of alkanes associated with oil. The biodegradation of alkanes rarely occurs by subterminal oxidation; however, it occurs by terminal hydroxylation to primary alcohol and here oxidation to a carboxylic acid. There are no attachment points in polyethylene except at the end of the carbon chain. This explains the limited reports of microbial activity on polyethylene. Activity is likely to be limited to lower molecular weight oligomers, in addition to the fragments and chemical groups introduced by photooxidation processes. Therefore, the introduction of functional chemical groups into polyethylene is likely to improve biodegradability.

\section{WASTE-TO-ENERGY (WTE)}

The processes involved in waste incineration for energy (WTE) would not be significantly affected by whether the incoming plastic is degradable or not, as $56 \%$ of the total energy that is generated during WTE waste incineration comes from urban biogenic organic waste (MSW). incineration of household waste generates energy, at least half of which is obtained in order not to increase the amount of $\mathrm{CO} 2$ in the biosphere. In other words, burning bio-based waste releases $\mathrm{CO} 2$ that has recently been captured and recovered during the production of new bio-based products, while burning fossil plastics releases $\mathrm{CO} 2$ that has been trapped for millions of years. Bio-based plastics can therefore be a good alternative to fossil plastics that are burned at the end of their life, e.g. B. Laminates or small volume plastics [5]. Another way to generate energy from waste is recovered solid fuel (SRF), which is made from non-hazardous waste. $\mathrm{SRF}$ is used for energy recovery in incineration/coincineration plants and must meet European requirements [EN 15359 solid fuels - specifications and classes]. This is what distinguishes SRF from Waste Derived Fuel (CDR), as $\mathrm{RDF}$ is not manufactured to CEN standards. The production of SRF / RDF from municipal solid waste offers an alternative to fossil fuels. SRF / RDF is used industrially in gasification and combustion processes as a fuel / co-fuel to generate electricity and heat [6]. Bio-based waste can be one of the raw materials for SRF production, although the limit values for environmentally harmful and toxic elements in SRF / RDF should be taken into account.

\section{Bio WASTE FOR FUELS AND CHEMICALS}

Both bio-based waste and organic waste can be used to produce fuel and this new approach is becoming increasingly important as a waste management method. The processes for producing fuel from these wastes include both biological and thermochemical conversions. Thermochemical methods for organic waste recovery include gasification, pyrolysis, tower fraction and hydrothermal carbonization [7]. Gasification is a new approach to organic waste management where dry or semi-dry raw material is paralyzed in a Gasifier to generate synthesis gas which is then purified, conditioned and sent for 
machination. According to Arduino et al. [8], the synthesis gas strategy shows better environmental performance and better carbon utilization than producing fossil fuels for road traffic. However, the technological availability is still too low and this seems economical only for plants with a capacity of 200 MW or more of biomass. On the other hand, the production of syngas seems to have greater potential for improvement, including the ability to produce not only biome thane but also chemicals with higher added value. [9].

\section{BIO-Plastics}

There are many misconceptions about the term "bio plastic". However, bio plastics include bio-based plastics or biodegradable plastics.

- Bio-based bio plastics contain part or all of their content or carbon obtained from renewable sources (animals, plants or microorganisms).

- Biodegradable plastic breaks down into methane (CH4), carbon dioxide (CO2), water (H2O) and biomass through biological action for a defined period and in defined environments - soil and marine environments, anaerobic fermentation and composting.

There is a common misconception between "bio based" and "biodegradable" polymers because they are inappropriately linked together. There is a subtle distinction as this is not the case, as a biodegradable bio plastic may not be bio based and a bio plastic based bio plastic may not be substantially biodegradable [eg. Polyethylene terephthalate and bio polyethylene] [10]. Biodegradation occurs in two stages. The first step is the decay (nb decay is a physical process while biodegradation is a chemical process. However, the two must occur together for complete decay to occur) of the polymers under appropriate conditions in the low varieties. Molecular weight by one of the two biotic reactions or photo degradation, hydrolysis or oxidation. The microbes remain, closely followed by the mineralization of the polymer. $\mathrm{H}$. Degradation by microbes or abiotic reactions.

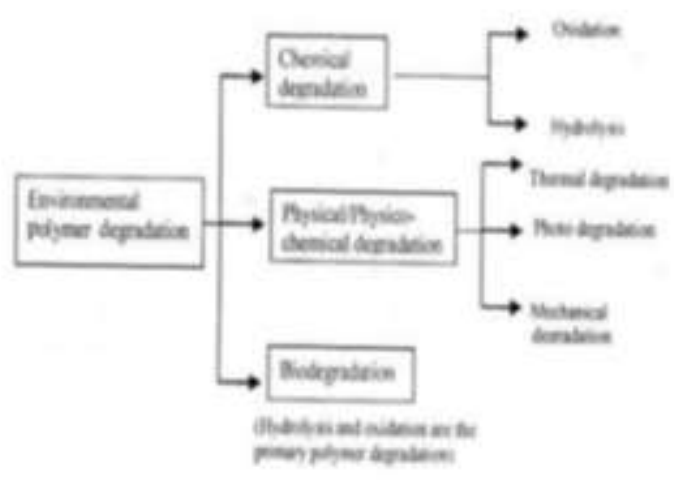

Fig. 1 Mechanisms of polymer degradation

\section{VII.BIODEGRADABLE PLASTICS FROM POLYESTERS}

Poly ( $\varepsilon$-caprolactone) has been found to be completely degradable when eliminated in bioactive environments such as soil [11]. These polyesters and their associated polyesters are hydrophobic and can be cast and extruded into sheets, bottles and a variety of discrete shaped articles, making this class of plastics prime targets for use as biodegradable plastics. Poly hydroxyl alkanets are biodegradable polyesters that can be produced from synthetic and bacterial layers directly from renewable raw materials. The most widely used polymer is poly (3-hydroxybutyrate) (PHB), a semicrystalline isotactic polymer that undergoes surface degradation due to its crystallinity and hydrophobicity of the spine. PHB has a glass change temperature of about $5^{\circ} \mathrm{C}$ and a dissolution temperature range of 160 to $180^{\circ} \mathrm{C}$. Hydrolytic degradation of PHB causes the arrangement of D - (-) - 3hydroxybutyric acid, a component typical of blood. The degradability, process ability and biocompatibility of PHB make it an incredible candidate for use in long distance tissue design applications. Unfortunately, PHB makes it a poor competitor for controlled release applications. The biodegradability and physical properties of PHAs can be controlled by mixing with natural or synthetic polymers. Zeneca PHBV Biopol @, a copolymerization of PHB with 3hydroxyvalerate, has received a lot of attention and has also been used in tissue engineering of tendons, bones, nerves, cartilage and skin. Although the addition of high voltage content improves the biomaterial capacity of PHB, the degradation rate remains extremely low for other biomedical applications. [12].

\section{CONCLUSION}

This paper presented the polymer characteristics as biodegradability and the west to energy and bio waste for fuel ad chemical. The description of bio plastics and biodegradable plastics based on polyester. Aromatic polyester is resistant to microbial attack due to its long aromatic oligomers. To obtain both good mechanical properties and biodegradability, aliphatic-aromatic polyesters are synthesized. It was also discovered that another widely used biodegradable thermosetting plastic, polyurethane, can be used by microorganisms as the sole source of carbon and nitrogen. As research into biodegradation of plastic waste intensifies, practical solutions to the environmental problems caused by plastic waste will soon emerge.

\section{REFERENCES}

[1] V.Boyaiah, Dr.V.Srinivas Rao “A Review on Usage of Non-Biodegradable Material in Construction Application" International Journal of Innovative Research in Science, Engineering and Technology, Vol. 6, Issue 9, September 2017. 
[2] F. Agostini, Cecilia Sundberg "Is biodegradable waste a porous environment? A review" DOI: 10.1177/0734242X12452444 July 2012.

[3] J. H. Song, R. J. Murphy "Biodegradable and compostable alternatives to conventional plastics" Philos Trans R SocLond B Biol Sci. 2009 Jul 27; 364(1526): 2127-2139.

[4] K Pikoń, Monika Czop "Environmental Impact of Biodegradable Packaging Waste Utilization" vol. 23, 3/2014.

[5] van den Oever, M.; Molenveld, K.; van der Zee, M.; Bos, H. Bio-based and biodegradable plasticsFacts and Figures. Wagening. Food Biobased Res. 2017, 1722, 33

[6] Nasrullah, M.; Hurme, M.; Oinas, P.; Hannula, J.; Vainikka, P. Influence of input waste feedstock on solid recovered fuel production in a mechanical treatment plant. Fuel Process. Technol. 2017, 163, 35-44.

[7] Berge, N.D.; Ro, K.S.; Mao, J.; Flora, J.R.V.; Chappell, M.A.; Bae, S. Hydrothermal carbonization of municipal waste streams. Environ. Sci. Technol. 2011, 45, 5696-5703.

[8] Ardolino, F.; Arena, U. Biowaste-to-biomethane: An LCA study on biogas and syngas roads. Waste Manag. 2019, 87, 441-453.

[9] Alamia, A.; Larsson, A.; Breitholtz, C.; Thunman, $\mathrm{H}$. Performance of large scale biomass gasifiers in a biorefinery, a state of the art reference. Int. J. Energy Res. 2017, 41, 2001-2019.

[10] Mashek, W. B., Krieger, P., \& Martin, K. (2016). Watching: Bioplastics. Plastics Market Watch. Washington, DC. Retrieved. plasticsportal.net/wa/plasticsEU bg_BG/function/co nversions:/publish/common/upload/biodegradable_p lastics/plastics_market_watch_bioplastics.pdf.

[11] Tokiwa, Y., Calabia, B. P., Ugwu, C. U., \&Aiba, S. (2009). Biodegradability of plastics. International Journal of Molecular Sciences, 10(9), 37223742 .

[12] Ulery, B. D., Nair, L. S., \& Laurencin, C. T. (2011). Biomedical applications of biodegradable polymers. Journal of Polymer Science, Part B: Polymer Physics, 49(12), 832-864. 